\title{
The Influence of Fertilizer Regimen on Water Chemistry and Filamentous Green Algae in Earthen-Substrate Ponds
}

\author{
Matthew J. Ward \\ South Dakota Department of Game, Fish and Parks, Blue Dog State Fish Hatchery \\ 44437 139A Street, Waubay, South Dakota, 57273, United States \\ Tel: 1-605-947-4657Ｅ-mail: matthew.ward@state.sd.us
}

\begin{abstract}
Received: December 22, 2021 Accepted: February 10, 2022 Published: February 14, 2022
doi: 10.52941/ast.v10i1.28 URL: https://doi.org/10.52941/ast.v10i1.28
\end{abstract}

\begin{abstract}
Water chemistry patterns can be indicative of production potential during pond culture of walleye (Sander vitreus, $\approx 30 \mathrm{~mm}$ total length). However, achieving desired water chemistry patterns that reflect an increase in zooplankton, a reduction in phytoplankton, and a lack of nuisance filamentous green algae in large, earthen-substrate ponds can be challenging. During 2020, water chemistry variables and the occurrence of filamentous green algae were compared in fishless, earthen-substrate ponds $(0.72 \mathrm{ha})$ that received either alfalfa meal $(\mathrm{AFM}, \mathrm{n}=2)$ or alfalfa meal combined with inorganic nitrogen (AFM+28:0:0, $n=2)$ over an approximate 30-day period. Alfalfa meal use was standard across all ponds $(476 \mathrm{~kg}$ ), while the concentration of inorganic nitrogen (ammonia- $\mathrm{N}+$ nitrate- $\mathrm{N}$ ) was initially raised to $1.25 \mathrm{mg} / \mathrm{L}$ with subsequent applications, at three to five-day intervals, having a target concentration of $0.64 \mathrm{mg} / \mathrm{L}$. Initial $\mathrm{pH}$ and dissolved oxygen were significantly higher, but $\mathrm{pH}$ became significantly lower over time in the AFM+28:0:0 treatment. Ammonia-nitrogen began similarly low $(<0.1 \mathrm{mg} / \mathrm{L})$ in both treatments but became and remained significantly higher (peaked $0.44 \mathrm{mg} / \mathrm{L}$ on June 9) with 28:0:0 supplementation. Nuisance, filamentous green algae were not observed with 28:0:0 supplementation but were present on the substrate of both ponds in the AFM treatment. Supplementing an alfalfa meal regimen with inorganic nitrogen every three to five days in earthen-substrate ponds deterred filamentous green algae and promoted water chemistry indicative of enhanced walleye fingerling production in previous trials.
\end{abstract}

Keywords: Walleye pond culture, Pond fertilization, Earthen-substrate ponds 


\section{Introduction}

Water chemistry patterns have been linked to increased walleye fingerling production in ponds at Blue Dog State Fish Hatchery. Decreasing dissolved oxygen (to $6.5 \mathrm{mg} / \mathrm{L}$ ) and $\mathrm{pH}$ (to < 8.2) and increasing ammonia-nitrogen concentration (to $0.3 \mathrm{mg} / \mathrm{L}$ ) during the second half of the approximate 35-day culture period corresponded with increased walleye production (Ward \& Blackwell, 2021). These water chemistry patterns are consistent with an increasing zooplankton biomass that has reduced phytoplankton (Qin \& Culver, 1995) as well as increasing decomposition of alfalfa fertilizer due to increased water temperatures (Boyd \& Tucker, 2014). The association between increased walleye production and increasing ammonia-nitrogen concentration suggest that consistently low $(<0.1 \mathrm{mg} / \mathrm{L})$ ammonia-nitrogen concentrations may limit fingerling production.

Achieving these water chemistry patterns in earthen-substrate ponds has been difficult when alfalfa is solely used. A standard regimen of alfalfa meal can result in ponds that experience substantially differing patterns in $\mathrm{pH}$, dissolved oxygen, and differing amounts of nuisance filamentous green algae (Ward \& Rasmus, 2021). Further, alfalfa regimens consistently result in low $(<0.1 \mathrm{mg} / \mathrm{L})$ ammonia-nitrogen concentrations in earthen-substrate ponds (Ward \& Blackwell, 2021; Ward \& Rasmus, 2021). Low ammonia-nitrogen concentrations may be a result of adsorption by muds or slow nutrient release characteristic of organic fertilizers (Boyd \& Tucker, 2014).

Nutrients in chemical fertilizers are immediately available to the biota (Hartleb et al. 2012) and therefore may improve availability of ammonium. Supplementing an alfalfa regimen with liquid $28 \mathrm{~N}: 0 \mathrm{P}: 0 \mathrm{~K}$ has shown potential for improved walleye production and the desired pattern in dissolved oxygen, pH, and ammonia-nitrogen (Ward and Rasmus 2021). The objective of this study was to compare water chemistry and the occurrence of filamentous green algae between fishless, earthen-substrate ponds that received either alfalfa meal only or alfalfa meal plus inorganic nitrogen.

\section{Method}

\subsection{Study Site and Design}

This study was conducted at Blue Dog State Fish Hatchery, Waubay, South Dakota, USA $\left(45^{\circ} 21^{\prime} 30.89^{\prime \prime N}, 97^{\circ} 19^{\prime} 03.63^{\prime \prime W}\right)$ during 2020. Four, earthen-substrate ponds (0.72 ha) were filled with unfiltered water from Blue Dog Lake (eutrophic, Stueven \& Bren, 1999) and fertilized with either an alfalfa meal only (AFM; $n=2$ ponds) or alfalfa meal plus inorganic nitrogen (AFM+28:0:0; $n=2$ ponds) regimen. All ponds received an initial application of 249 kilograms of alfalfa meal on May 21 as they were filling. Subsequent alfalfa meal applications consisted of 113 kilograms on May 28 and June 9 in all ponds. Liquid 28:0:0 (N:P:K) was added to the AFM+28:0:0 regimen at three to five day intervals beginning on May 24. The target concentration for inorganic nitrogen was $1.25 \mathrm{mg} / \mathrm{L}$ for the initial application, but all subsequent 
applications raised inorganic nitrogen to $0.64 \mathrm{mg} / \mathrm{L}$. To determine the volume of 28:0:0 to apply, a Hach DR2010 Spectrophotometer (Loveland, Colorado, USA) was first used to measure ammonia- (mg/L, salicylate method) and nitrate-nitrogen $(\mathrm{mg} / \mathrm{L}$, cadmium reduction method) within pond water. These values were used in the following formula where target, ammonia, and nitrate concentrations are in milligrams per cubic meter. Pond volume was assumed to be 8,437 cubic meters based on historical hatchery estimates and nitrogen concentration of 28:0:0 fertilizer was 456,000 milligrams per liter based on label specifications including a fertilizer density of 1.27 kilograms per liter that is $28 \%$ nitrogen and has a specific gravity of 1.281 .

Liters of 28:0:0 required $=(($ target concentration $-($ ammonia-nitrogen concentration $)-$ nitrate-nitrogen concentration)) * pond volume) / nitrogen concentration in 28:0:0

\subsection{Water Chemistry and Filamentous Green Algae}

Dissolved oxygen (mg/L; Oakton PD 450 meter with RDO probe and sensor cap, Oakton Instruments, Vernon Hills, Illinois), pH (Oakton pH 150 meter with electrode, Oakton Instruments, Vernon Hills, Illinois), and water temperature $\left({ }^{\circ}\right.$ Celsius; same equipment as dissolved oxygen) were measured twice daily (9 a.m. and 3 p.m.) on May 28, June 4, 9, and 17. Ammonia-nitrogen (mg/L; salicylate method) and nitrate-nitrogen ( $\mathrm{mg} / \mathrm{L}$; cadmium reduction method) were measured on the same days but only during a.m. hours. Total alkalinity (mg $\mathrm{CaCO}_{3} / \mathrm{L}$; sulfuric acid titration to $\mathrm{pH} 4.8$, Hack Kit, Loveland, Colorado, USA) remained above 150 in all ponds throughout the study. The presence or absence of filamentous green algae were noted as each pond was drained on June 25.

\subsection{Statistics}

Means and standard errors were used to describe water chemistry parameters over time. Data did not differ significantly from a normal distribution (Anderson-Darling test, p-value > 0.15), and a one-way analysis of variance was used to compare water chemistry parameters between fertilization treatments with a significance level of 0.05 .

\section{Results}

\subsection{Water Chemistry}

Ammonia-nitrogen steadily increased from < $0.1 \mathrm{mg} / \mathrm{L}$ on May 28 to $0.44 \mathrm{mg} / \mathrm{L}$ on June 9 before decreasing to $0.1 \mathrm{mg} / \mathrm{L}$ on June 17 in the AFM+28:0:0 treatment. Ammonia-nitrogen was significantly higher in the AFM+28:0:0 treatment on June 4, 9, and 17 compared to the AFM treatment which consistently exhibited concentrations below $0.1 \mathrm{mg} / \mathrm{L}$ (Figure 1).

The AFM+28:0:0 treatment exhibited significantly higher $\mathrm{pH}$ on May 28 (a.m. period), but significantly lower pH on June 9 (a.m. and p.m.) and 17 (a.m.). Both treatments exhibited pH that steadily decreased to below 8.2 on June 9 followed by an increase on June 17 (Figure 2).

Similar to $\mathrm{pH}$, both treatments exhibited a general decreasing trend in dissolved oxygen through 
June 9 at which time concentrations approached $6.5 \mathrm{mg} / \mathrm{L}$. Dissolved oxygen was significantly higher in the AFM+28:0:0 treatment on May 28 during both a.m. and p.m. periods, but no significant differences were found between treatments on June 4, 9, and 17 (Figure 3).

Water temperature was not significantly different at any sampling date (Figure 4).

\subsection{Filamentous Green Algae}

Large mats of filamentous green algae coated the substrate of both ponds in the AFM treatment during draining on June 25. In the AFM+28:0:0 treatment, filamentous algae were not observed in either pond during draining.

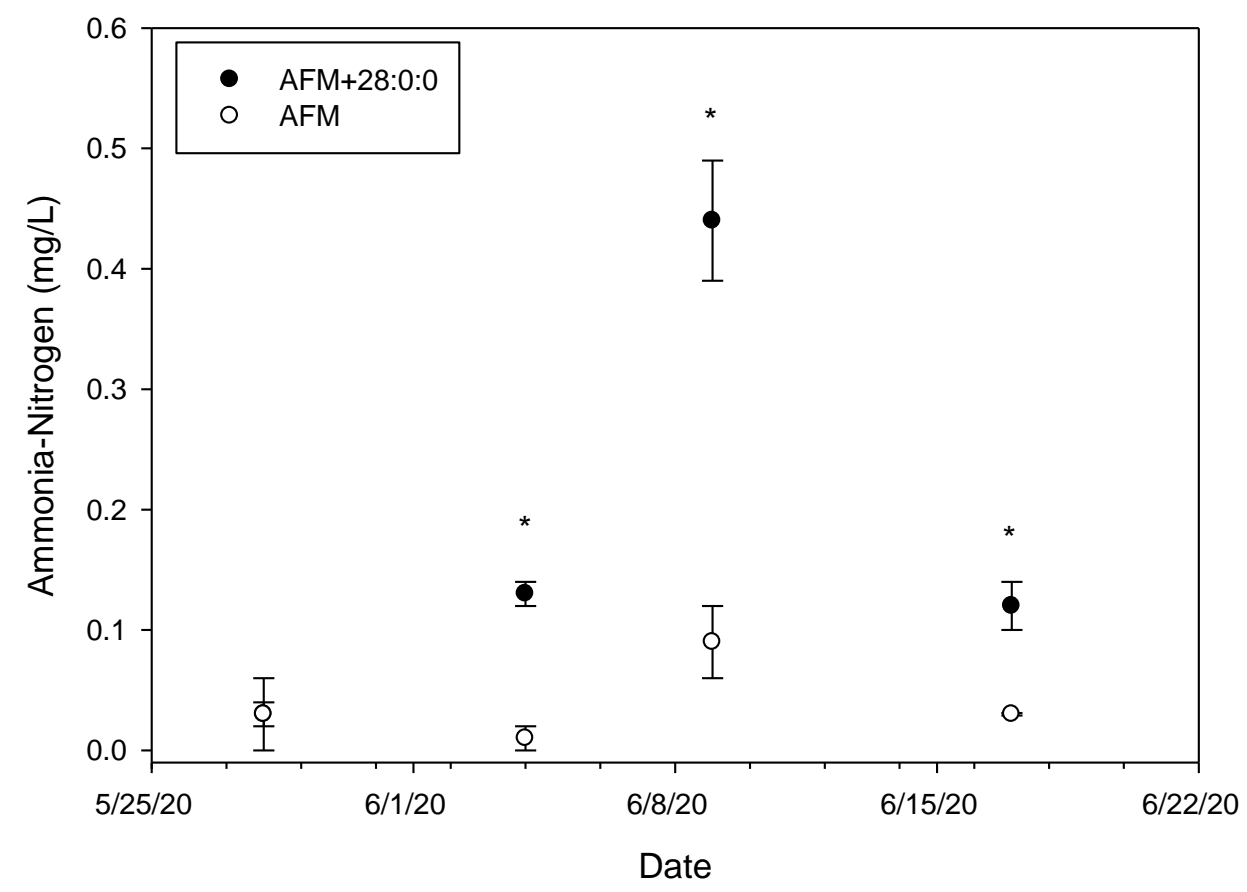

Figure 1. Mean $( \pm$ SE) ammonia-nitrogen concentration in earthen-substrate ponds that received either alfalfa meal plus liquid nitrogen supplementation (filled circles) or alfalfa meal only (unfilled). An asterisk indicates a significant difference $(P \leq 0.05)$ between fertilizer treatments on that date.

\section{Discussion}

The AFM+28:0:0 treatment exhibited higher ammonia-nitrogen concentration between June 4 and 17 compared to the AFM treatment. Ammonia-nitrogen concentration remained below 0.1 $\mathrm{mg} / \mathrm{L}$ in the AFM treatment, which is consistent when organic fertilizers are solely used in 
earthen-substrate ponds at this hatchery (Ward \& Blackwell, 2021; Ward \& Rasmus, 2021). In the AFM+28:0:0 treatment, ammonia-nitrogen peaked on June 9 at $0.44 \mathrm{mg} / \mathrm{L}$ and slightly exceeded the recommended concentration of $0.3 \mathrm{mg} / \mathrm{L}$ during the second half of the culture period (Ward \& Blackwell, 2021). The peak ammonia-nitrogen concentration occurred at a time when phytoplankton can be overgrazed by zooplankton especially when fish density is reduced (Qin \& Culver, 1995). Supplementing an alfalfa meal regimen with 28:0:0 every three to five days was effective at increasing ammonia-nitrogen concentration during the latter half of the culture period in earthen-substrate ponds.

Initially higher dissolved oxygen and $\mathrm{pH}$ in the AFM+28:0:0 treatment reflect increased photosynthetic activity compared to the AFM treatment. The general decline in $\mathrm{pH}$ and dissolved oxygen in both treatments through June 9 may be attributed to the decomposition of the alfalfa meal (Boyd \& Tucker, 2014) and a reduction in photosynthetic activity presumably caused by zooplankton overgrazing phytoplankton (Qin \& Culver, 1995). The significantly 

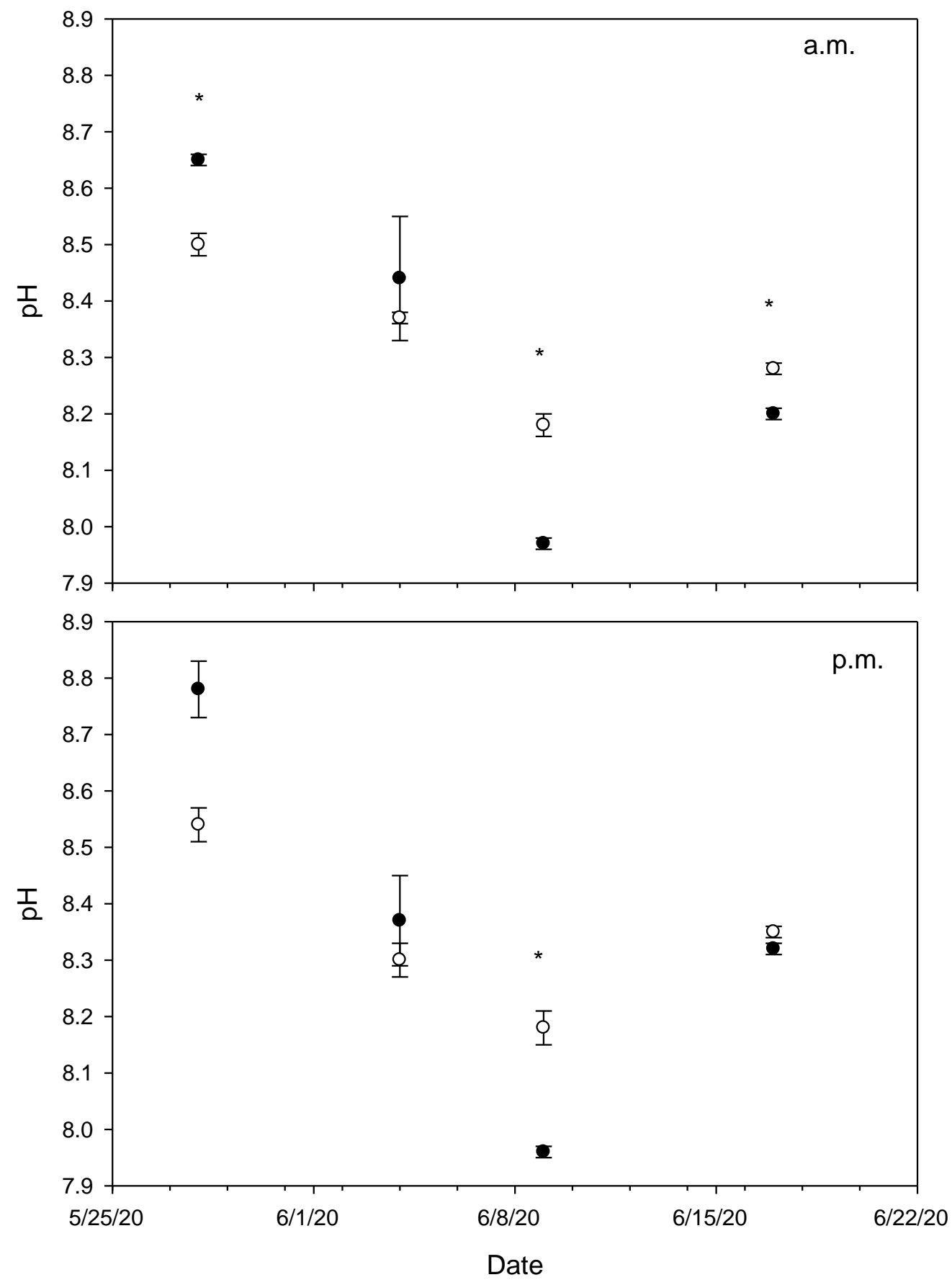

- $\mathrm{AFM+28:0:0}$

O AFM

Figure 2. Mean $( \pm \mathrm{SE}) \mathrm{pH}$ values for earthen-substrate ponds that received either alfalfa meal plus liquid nitrogen supplementation (filled circles) or alfalfa meal only (unfilled) for both a.m. and p.m. periods. An asterisk indicates a significant difference $(P \leq 0.05)$ between fertilizer treatments on that date. 

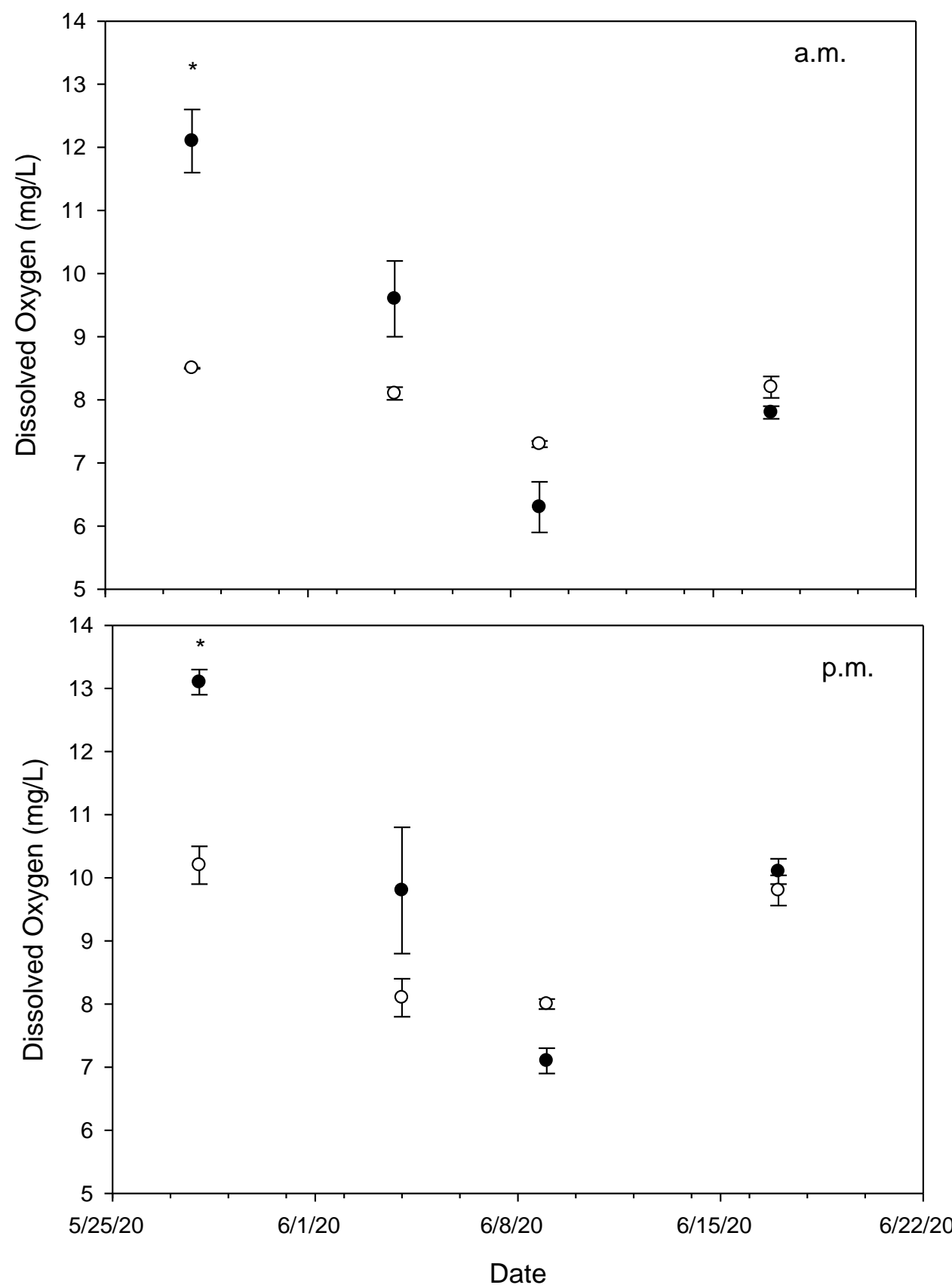

- $\mathrm{AFM}+28: 0: 0$

$\circ$ AFM

Figure 3. Mean $( \pm \mathrm{SE})$ dissolved oxygen concentration values for earthen-substrate ponds that received either alfalfa meal plus liquid nitrogen supplementation (filled circles) or alfalfa meal only (unfilled) for both a.m. and p.m. periods. An asterisk indicates a significant difference $(P \leq 0.05)$ between fertilizer treatments on that date. 

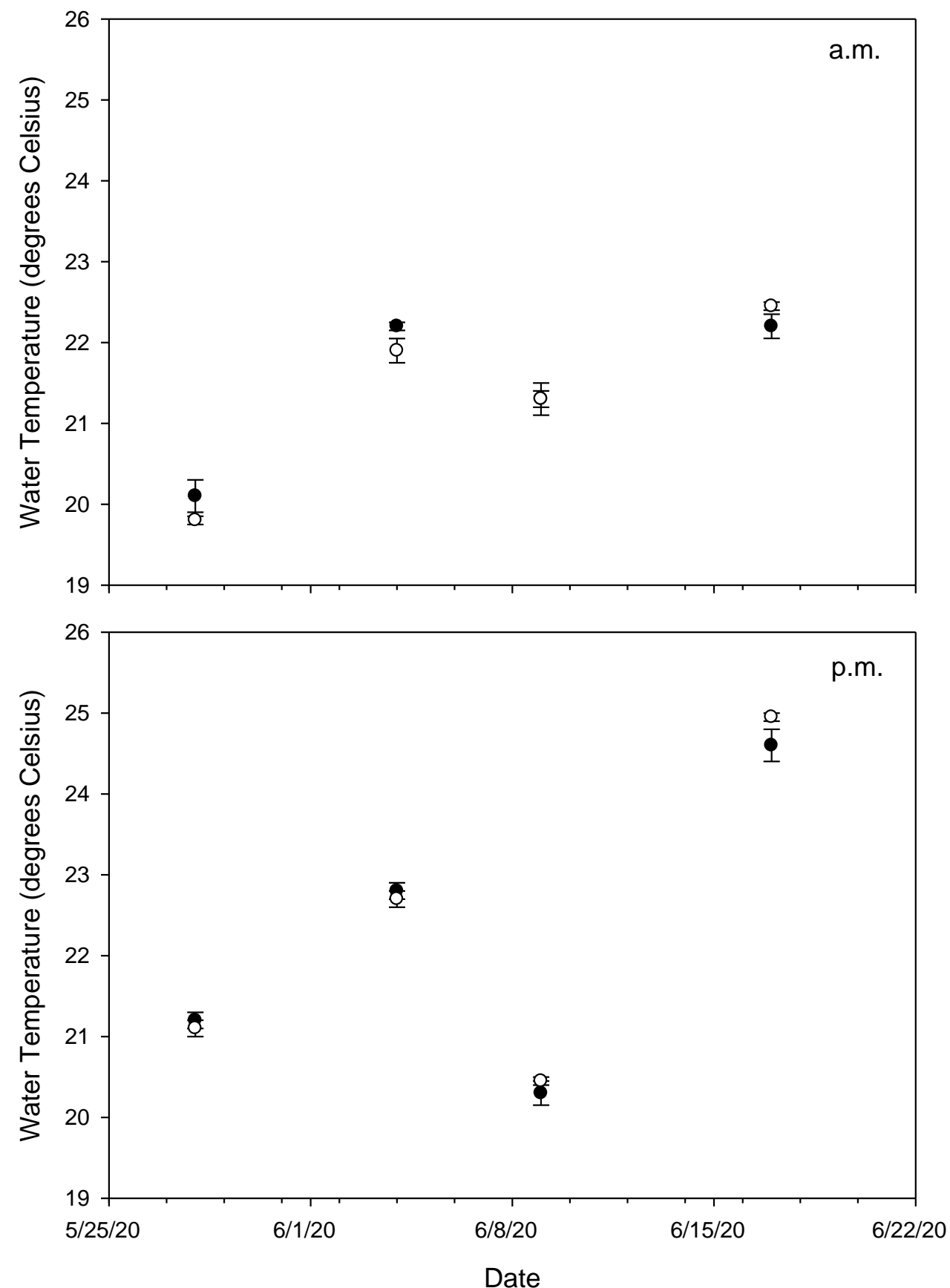

- $\mathrm{AFM+28:0:0}$

O AFM

Figure 4. Mean $( \pm$ SE) water temperature for earthen-substrate ponds that received either alfalfa meal plus liquid nitrogen (filled circles) or alfalfa meal only (unfilled) for both a.m. and p.m. timeframes. No significant differences were found between fertilizer treatments $(P>0.05)$. 
lower $\mathrm{pH}$ on June 9 and 17 in the AFM+28:0:0 treatment suggests processes governing $\mathrm{pH}$ (e.g., decomposition and photosynthesis) were altered compared to the AFM treatment. Both fertilizer treatments exhibited a reduction in dissolved oxygen and $\mathrm{pH}$ through June 9 and exhibited values close to recommendations (Ward \& Blackwell, 2021); however, the $\mathrm{AFM}+28: 0: 0$ treatment emphasized the $\mathrm{pH}$ reduction during the second half of the study period.

Filamentous green algae were absent during pond draining in AFM+28:0:0 treatment, but present within the AFM treatment. The negative aspects of filamentous green algae are well known and include loss of fish due to entanglement (Culver, 1996), increased workload during pond harvest (Hartleb et al., 2012) and inefficiencies within the food web that can reduce walleye production (Hartleb et al., 2012; Ward \& Rasmus, 2021). Increasing nitrogen input via regular 28:0:0 supplementation deterred filamentous green algae in this study. The presence of filamentous green algae towards the end of the study may have contributed to the higher $\mathrm{pH}$ values that occurred in the AFM treatment (Ward \& Rasmus, 2021).

Supplementing an alfalfa meal regimen with inorganic nitrogen every three to five days in earthen-substrate ponds deterred filamentous green algae and promoted water chemistry indicative of enhanced walleye fingerling production in previous trials. Ward \& Blackwell, (2021) recommended manipulating fertilization to promote a reduction in dissolved oxygen to $6.5 \mathrm{mg} / \mathrm{L}$ and $\mathrm{pH}$ to 8.0 - 8.2, while increasing ammonia-nitrogen to $0.3 \mathrm{mg} / \mathrm{L}$ during the second half of the culture period in earthen-substrate ponds as these values coincided with increased walleye production. Future studies should include an assessment of walleye production metrics along with water chemistry parameters for both AFM and AFM+28:0:0 regimens in earthen-substrate ponds at Blue Dog Hatchery.

\section{Acknowledgments}

Thanks to J. Broughton, R. Smidt, R. Rasmus, N. Pool, and C. Haabala for their efforts in the collection and publication of these data.

\section{References}

Boyd, C. E., \& Tucker, C. S. (2014). Handbook for Aquaculture Water Quality, Craftmasters Printers, Inc., Auburn, Alabama.

Culver, D. A. (1996). Fertilization procedures for pond culture of walleye and saugeye. In R.C. Summerfelt (Ed.) Walleye Culture Manual, 115-122. North Central Regional Aquaculture Center Publications Office, Iowa State University, Ames.

Hartleb, C. F., Johnson, J. A., \& Held, J. A. (2012). Walleye and yellow perch pond fertilization. In C.C. Mischke (Ed.) Aquaculture Pond Fertilization: Impacts of Nutrient Input on Production, 147-161. Wiley-Blackwell, Oxford.

Qin, J., \& Culver, D. A. (1995). Effect of young-of-the-year walleye (Percidae: Stizostedion vitreum) on plankton dynamics and water quality in ponds. Hydrobiologia, 297, 217-227. 
https://doi.org/10.1007/BF00019286

Stueven, E. H., \& Bren, R. (1999). Phase 1 watershed assessment final report, Blue Dog Lake, Day County, South Dakota. South Dakota Department of Environment and Natural Resources, Pierre.

Ward, M. J., \& Blackwell, B. G. (2021). Factors associated with increased walleye production in lined compared to earthen-substrate ponds. Open Journal of Animal Sciences, 11, 50-61. doi: 10.4236/ojas.2021.111005

Ward, M. J., \& Rasmus, R. A. (2021). Filamentous green algae reduce walleye fingerling production in earthen-substrate ponds. Open Journal of Animal Sciences, 11, 157-163. doi: 10.4236/ojas.2021.112012

\section{Copyrights}

Copyright for this article is retained by the author(s), with first publication rights granted to the journal.

This is an open-access article distributed under the terms and conditions of the Creative Commons Attribution license (http://creativecommons.org/licenses/by/4.0/) 